Acta Hispanica (2016) 21: 143-156

\title{
EL IMPACTO DEL BOOM LATINOAMERICANO EN LOS ESCRITORES SERBIOS ${ }^{1}$
}

\section{Bojana Kovačević Petrović}

\author{
Universidad de Novi Sad
}

\begin{abstract}
Resumen: En este trabajo queremos mostrar los fuertes vínculos entre los escritores hispanoamericanos y serbios, a través de los libros traducidos del español y las obras escritas en serbio. Suponiendo que cada escritor es, sobre todo, un buen lector, y teniendo en cuenta la importancia de la traducción para la literatura en general, hemos investigando la influencia de Borges, Cortázar, Fuentes, García Márquez o Vargas Llosa en los escritores serbios desde los años 50 del siglo XX hasta hoy. A través de testimonios auténticos -entrevistas hechas a propósito de la investigación- y el repaso y análisis de los libros $\mathrm{y}$ textos particulares influidos por los autores del boom, presentaremos una variedad creativa y una creación literaria auténtica de un pequeño país con grandes literatos, para mostrar que el gran impacto de la literatura hispanoamericana en Serbia empezó hace medio siglo y nunca cesó.
\end{abstract}

Palabras clave: boom de la literatura hispanoamericana, literatura latinoamericana, literatura serbia, traducción

\begin{abstract}
In this work we want to show the strong links between Spanish-American and Serbian writers, through the books translated from Spanish and works written in Serbian. Assuming that each writer is above all a good reader, and considering the importance of translation for literature in general, we have investigated the influence of Borges, Cortázar, Fuentes, García Márquez and Vargas Llosa on Serbian writers since the 1950s until today. Through authentic testimonies - interviews made for this research - and the reviews and analysis of books and particular texts influenced by the authors of the boom, we will present a creative variety and authentic literary creation of a small country with many translations and dedicated writers, and show that the great impact of Spanish-American literature in Serbia began half a century ago and never ceased.
\end{abstract}

Keywords: Latin-American literary boom, Serbian literature, Spanish-American Literature, Translation

\footnotetext{
1 Este artículo forma parte del proyecto CEEPUS "La recepción europea de la literatura latinoamericana moderna. Los casos de Albania, Bulgaria, Croacia, Eslovaquia, Eslovenia, Hungría, Italia, Polonia, Portugal, República Checa, Rumanía y Serbia” de la Red de Hispanistas de Europa Central y fue comunicado en el IV Coloquio internacional de jóvenes investigadores de literatura hispanoamericana: El escritor en su laberinto: lecturas, relecturas y deslecturas de la literatura bispanoamericana en la Universidad Complutense de Madrid, el 19 de mayo 2016.
} 
El impacto del boom latinoamericano en los escritores serbios

\section{Reflexiones introductorias: libros, autores y traductores}

La larga trayectoria de la relación entre la nueva novela hispanoamericana y la prosa serbia actual empezó en 1969, con la primera obra del boom hispanoamericano publicada en el territorio de Yugoslavia: La muerte de Artemio Cruz de Carlos Fuentes, traducida por Edita Marijanović y epilogada por Dalibor Soldatić. ${ }^{2}$ Un punto fundamental para el desarrollo del interés de los traductores y escritores serbios en la literatura hispanoamericana ocurrió dos años después, en 1971, cuando dentro del Departamento de Lenguas Romances de la Facultad de Filología de la Universidad de Belgrado fue fundado el Grupo de Lengua y Literatura española, gracias a los esfuerzos de la primera jefa del futuro Departamento, la Dra. Ljiljana Pavlović Samurović. ${ }^{3}$ El Departamento produjo centenas de hispanistas en más de cuatro décadas, y entre ellos varios traductores, que crearon las traducciones de poesía, cuentos, novelas, ensayos y obras de teatro de los autores de habla hispana. ${ }^{4}$

Hay muchos autores serbios influidos por el boom, cuya afición a los escritores hispanoamericanos sigue poco conocida en Serbia, y todavía menos en otros países e idiomas. En este artículo destacaremos a unos de ellos, que consideramos significantes para nuestro tema: el académico Milorad Pavić, autor del Diccionario jázaro ${ }^{5}$, escribió inspirado por el realismo mágico la novela que tuvo un enorme éxito en el mundo y se distinguió entre los narradores serbios modernos e innovadores; Goran Petrović creó El cerco de la Iglesia de la Santa Salvación ${ }^{6}$ tras leer Terra Nostra de Carlos Fuentes y tuvo gran éxito en

2 Véase el panorama de las literaturas hispánicas en Serbia ofrecido por Soldatić, uno de los hispanistas serbios más apreciados hoy en día, en el primer número de la revista Colindancias de la Red de Hispanistas de Europa Central: https://dialnet.unirioja.es/revista/23680/A/2010, fecha de consulta: 21 de mayo de 2016.

${ }^{3}$ El Grupo, unos años después, amplió el programa y cambió de nombre en Grupo de Lengua Española y Literaturas Hispánicas y, en el año 2000, se transformó en Cátedra de Estudios Ibéricos.

4 Varias investigaciones sobre las traducciones de las obras hispanoamericanas al serbio y su recepción ha hecho la profesora de la Facultad de Filología de Belgrado, Vesna DICKOV. Entre sus artículos figuran varios escritos en español: "La poesía hispanoamericana en Serbia", in: Colindancias, 2013/14, Timisoara, 43-57; "Las literaturas hispánicas y el pensamiento crítico y teórico serbio", in: Colindancias 2014/15, Timisoara, 75-102; "La crítica de la obra narrativa de Gabriel García Márquez en las revistas literarias serbias", in: Verba Hispánica, 22/1, Ljubljana, 2014, 91-104; "La relación de Mario Vargas Llosa con la realidad: su reflejo en las revistas literarias serbias", in: Transiciones: de la dictadura a la democracia, (eds.: Tibor BERTA, Zsuzsanna CSIKÓS, Katalin JANCSÓ, Eszter KATONA, András LÉNÁRT, Veronika PRAEFORT), Szeged, Universidad de Szeged, 2016.

5 Traducción española: Diccionario jázaro: novela léxico en 100.000 palabras, Barcelona, Anagrama, 1989. Traducción del serbocroata por Dalibor Soldatić. Ejemplar masculino ISBN 84-339-3172-5; Ejemplar femenino ISBN 84-339-3173-3. Véase: https://www.anagrama-ed.es/libro/panoramade-narrativas/diccionario-jazaro-ejemplar-masculino-/9788433932013/PN_172, fecha de consulta: 26 de abril de 2016.

${ }^{6}$ Traducción española: El cerco de la iglesia de la Santa Salvación, México D.F., Editorial Sexto Piso, 2012. Traducción del serbio por Dubravka Sužnjević ISBN 978-607-7781-34-9. Véase: 
México con ocho libros traducidos en español por Dubravka Sužnjević. El escritor premiado y profesor de literatura serbia Sava Damjanov transmitió su libro favorito, Aura del escritor mexicano, a miles de sus estudiantes de la Universidad de Novi Sad y nos comentó para este artículo sus impresiones tras leer por primera vez la novela de Carlos Fuentes, traducida por Branko Anđić; el escritor y editor Jovica Aćin apoyó la publicación de los Cuentos completos de Julio Cortázar traducidos por Aleksandra Mančić, traductora de decenas de libros españoles e hispanoamericanos -desde Historia de Mayta de Vargas Llosa (1987) hasta el Don Quijote (2011). Uglješa Šajtinac, laureado del European Union Prize for Literature 2015, otro aficionado a la literatura hispanoamericana en Serbia, compartió con nosotros su gran interés en la obra de Vargas Llosa. Vasa Pavković editó una decena de novelas latinoamericanas y compuso una recopilación titulada Proyecto Cortázar, donde reunió a quince escritores serbios que escribieron para esa antología cuentos inspirados por el escritor argentino. Aparte de los escritores mencionados, hay muchos más que escribieron cuentos, artículos, críticas, reseñas o reflexiones sobre la literatura hispanoamericana en idioma serbio (Vasko Popa, el gran admirador de Jorge Luis Borges; Milisav Savić cuya obra está impregnada de los pensamientos de Borges y Carlos Fuentes; Mihajlo Pantić, autor de varios ensayos y reflexiones sobre Borges; Dragan Jovanović Danilov, confiado que Carlos Fuentes es el escritor más distinguido de la literatura hispanoamericana; Đorde Pisarev, el autor de una decena de artículos sobre los autores mencionados, etc.).

También hace falta destacar dos importantes libros relacionados con la literatura hispanoamericana, cuyos autores son los pioneros del hispanismo en Serbia: Leksikon bispanoamericke književnosti (Diccionario de la literatura hispanoamericana, 1993) de Ljiljana Pavlović Samurović, cuya estructura "está determinada por la complejidad y abundancia de su contenido, que es tratado desde el punto de vista histórico, teórico y crítico literario"7 y Prilozi za teoriju novog hispanoameričkog romana (Las contribuciones a la teoría de la nueva novela hispanoamericana, 2002) de Dalibor Soldatić, que abarca sus puntos de vista "teórico y crítico literarios con respecto a la nueva novela hispanoamericana y su relación con la realidad, el análisis del pensamiento teórico de algunos escritores hispanoamericanos y la interpretación del estatus de la novela en la literatura hispanoamericana en general."

http://sextopiso.mx/tienda/cerco-de-la-iglesia-de-la-santa-salvacion/, fecha de consulta: 29 de abril de 2016.

${ }^{7}$ Vesna DiCKOv, “Las literaturas hispánicas...”, op. cit., 94.

8 Ibidem, 97. 
El impacto del boom latinoamericano en los escritores serbios

\section{Borges y el preboom}

Uno de los escritores hispanoamericanos que tuvo mayor impacto en varias generaciones de escritores yugoslavos y serbios fue Jorge Luis Borges, "uno de pocos escritores que se dio cuenta hasta qué punto alcanzan los límites de la literatura." Su primer libro publicado en Serbia fue Ficciones ${ }^{10}$, en 1963, pero en los círculos literarios de esa época todavía no había mucho interés por los escritores hispanoamericanos. Por lo visto, tampoco hubo mucha reacción cuando se publicaron los primeros libros de Juan Rulfo $^{11}$ y Julio Cortázar ${ }^{12}$. Un interés más amplio, sin embargo, vino con las décadas de los setenta y ochenta ${ }^{13}$, siendo el momento más importante para los muchos escritores serbios aficionado a Borges el Simposio Internacional científico-literario dedicado a la obra del escritor argentino, a propósito de los diez años de su fallecimiento, que tuvo lugar en Belgrado en 1996 y contó con la presencia de María Kodama. Un año después se publicó un compendio que recogió todos los trabajos leídos en el Simposio "a fin de poner de pleno relieve la importancia del influjo ejercido por las posiciones intelectuales que Borges transmite en sus narraciones, ensayos y versos, así como por el sistema poético suyo con respeto a la literatura serbia contemporánea."14 Las actas embarcan 67 textos de más de 50 autores: poetas, críticos, ensayistas, cuentistas y periodistas, casi todos serbios. Entre muchas cosas importantes escritas y dichas, queremos subrayar unas cuantas: Branko Anđić15 advierte que "tan solo después de su fallecimiento, los argentinos

\footnotetext{
${ }^{9}$ Milan R. SIMIĆ, Dnevnik čitaoca, Zrenjanin, Agora, 2015, 5. Jedan od retkih književnika koji je doznao dokle se protežu krajnje književne granice. (Tr. aut.)

10 Traducción serbia: Maśtarije, Nolit, Belgrado 1963, traducción (del francés) de Božidar Marković, prólogo de Miodrag Pavlović.

${ }_{11}$ Traducción serbia: Pedro Páramo, Nolit, Belgrado, 1966, traducción de Radoje Tatić, prólogo de R. Tatić y Juan Octavio Prenz.

${ }^{12}$ Las armas secretas, Tajno orušje (cuentos de tres libros de Julio Cortázar: Final del juego, Bestiario y Las armas secretas), Nolit, Belgrado, 1969, traducción y prólogo de Radoje Tatić.

${ }^{13}$ Uno de los editores y literatas serbios que dio un gran impacto en la recepción de la obra de Borges en Yugoslavia fue Radivoje Konstantinović, traductor y profesor universitario. Aparte de escribir prefacios y epílogos para las traducciones serbias del autor argentino, Konstantinović escribió sobre Borges en su libro de ensayos Istrą̌ivanje tišine $i$ drugi ogledi (Investigación del silencio y otros ensayos, Srpska književna zadruga, Belgrado, 1995) y en varios periódicos y revistas.

${ }^{14}$ Filip MATIĆ y Marko NEDIĆ, "Notas de introducción”, in: Borges. Actas del Congreso Internacional dedicado a J. L Borges, Belgrado, 24-25 septiembre de 1996. Radivoje KONSTANTINOVIĆ, Filip MATIĆ y Marko NEDIĆ (eds.), Zavod za ud乏̌benike i nastavna sredstva: Srpska knjižerna zadruga: Jugoslovensko udruženje latinoamerikanista, Belgrado, 1997, 19.

${ }^{15} \mathrm{El}$ traductor y escritor Branko Anđić, residente en Argentina desde hace veinte años, conoció, tradujo y trajo a Serbia decenas de escritores hispanoamericanos (sobre todo argentinos) en las últimas décadas: Liliana Heer, Ana María Shua, Luisa Valenzuela, Guillermo Martínez, Samanta Schweblin y como editor abrió paso a los autores canónicos hispanoamericanos. Aparte de
} 
admitieron que Borges también era argentino"16; Milisav Savić "somete a un juego de fino humor la idea básica de Borges que la realidad es un invento de la literatura"17; José Emilio Pacheco afirma que "Borges formaba parte de la literatura serbia"18 y Milorad Pavić destaca que "Jorge Luis Borges es el escritor más grande de nuestros tiempos."19 Entre los autores que escribían en el idioma serbio, hay que poner atención especial a Danilo Kiš, cuya obra siempre estaba relacionada con la de Borges -tanto que le llamaban "el Borges serbio"- y quien apuntó sus reflexiones sobre el autor argentino en sus libros de ensayos Skladiste (Almacén, 1995), Eseji: autopoetike (2000); además, su libro que abarca siete novelas cortas, Grobnica za Borisa Davidoviča (Una tumba para Boris Davidovich20, 1976) ha sido gestionado como diálogo o réplica de la Historia Universal de la Infamia de Borges. Otros autores serbios, Jovan Delić y Svetislav Jovanov, publicaron artículos titulados, respectivamente, "Danilo Kiš y J. L. Borges"21 y "Upotreba minotaura: Kiš i Borhes” ("El uso de minotauro: Kiš y Borges") 22 y entre varios artículos y obras serbios dedicados a Kiš y a Borges, hay que destacar el libro de ensayos Kiš, Borhes, Maradona de Božo Koprivica (Narodna knjiga, Beograd, 1996), Njuškači jabuka del ilustre escritor y matemático serbio Vladimir Tasić (Svetovi, Novi Sad, 2005) o Minuli mrak (Oscuridad apaciguada, Svetovi, Novi Sad, 2004) de distinguido Draško Ređep.

Otro autor que cabe mencionar es el poeta serbio (de origen rumano) más traducido desde la Segunda Guerra Mundial, Vasko Popa, miembro de la Academia Serbia de Ciencias y Artes. Su poema "Pesnikov hleb" ("El pan del poeta") refleja uno de sus encuentros con Jorge Luis Borges producido, se supone, en 1981 en el Festival Internacional de Poesía de Morelia (México). ${ }^{23}$ En el mencionado poema, Popa expresa que, en la ocasión de su primer encuentro, el argentino le preguntó cómo se decía la palabra pan en serbio, y en otras circunstancias, muchos años después, se acordó de esa palabra (bleb). En 1987, en el Congreso Internacional El universo de Jorge Luis Borges, celebrado en Buenos Aires, Vasko Popa escribió un poema inspirado por el escritor argentino, "El Buenos Aires de Borges". ${ }^{4}$ A propósito de este artículo, Jovica Aćin nos

producir un gran impacto de la literatura hispanoamericana en Serbia, también hizo un fuerte vínculo entre los literatos y traductores de los dos continentes.

${ }^{16}$ Ibidem, 74.

${ }^{17}$ Ibidem, 93.

18 Ibidem, 281.

${ }^{19}$ Ibidem, 287. “Horhe Luis Borhes je najveći pisac današnjice.” (Trad. aut.)

${ }^{20}$ Véase: http://www.acantilado.es/catalogo/una-tumba-para-boris-davidovich-300.htm, fecha de consulta: 2 de mayo de 2016.

${ }^{21}$ Letopis Matice srpske, 453/3 (marzo de 1994), 347-352.

22 Polja: meseřnik za umetnost $i$ kulturu. 403/404, 1997, 9-11.

${ }^{23}$ Véase: http://elpais.com/diario/1981/08/26/cultura/367624807_850215.html, fecha de consulta: 12 de mayo de 2016.

${ }^{24}$ Los espejos inconmensurables de / Buenos Aires recordaron / el tango, que al filo / de los sueños y del cuchillo / Borges bailó y bailó hasta el fin: / los espejos continuados y multiplicados / 
contó una anécdota relacionada con la invitación que Popa recibió para participar en el Congreso Internacional en la capital argentina, dedicado a Borges. Popa iba a viajar a Argentina y no tenía ningún ejemplar de la traducción de Ficciones de 1963, que debía llevar a la exposición de Buenos Aires. Se acordó de mí y me pidió mi ejemplar. A duras penas me esforcé por no rechazarle, me resultó difícil separarme del libro. Al final me amenazó que terminaría con nuestra amistad. En otras palabras, le di mi ejemplar y él se lo llevó a Buenos Aires. Ese libro, con todas mis notas, se ha quedado para siempre en la Biblioteca de Borges. ${ }^{25}$

En este artículo no disponemos de suficiente espacio para profundizar las relaciones literarias entre Popa y Borges, pero queremos destacar que en 2012 en México se publicó Obra completa de Vasko Popa (Editorial Vaso Roto), traducido al español por Dubravka Sužnjević26 ${ }^{2}$ y mencionado en el suplemento Babelia de El País, dentro de la lista de los mejores libros del año 2013.

Muchos escritores en Serbia han escrito sobre Borges y han sido inspirados por él en los últimos cincuenta años -solo hemos mencionado alguno de ellos 27 , y sería imprescindible dedicar una de las futuras investigaciones a ese tema importantísimo tanto para la literatura serbia como para la literatura argentina e hispanoamericana.

cien veces ese tango, entonces / lentamente, el baile le ofrece / una salida del laberinto / de calles y de dudas. // (Traducción: Armando Blažina)

25 "Popa je putovao u Argentinu, ali nije imao primerak Maśtarija iz 1963, koji je trebalo da ponese na tu izložbu. Setio se mene i tražio mi moj primerak. Teško mi je bilo da ga odbijem, a teško mi je bilo i da se rastanem s knjigom. Naposletku mi je zapretio da će raskinuti naše prijateljstvo. Ukratko, knjigu sam mu dao i on ju je odneo u Buenos Ajres. Sad je taj primerak, sa svim mojim beleškama, zauvek u Borhesovoj biblioteci." (Trad. aut.) Jovica Aćin, Comunicación personal, 11 de junio 2016.

${ }^{26}$ Véase http:/ / www.vasoroto.com/?lg=es\&id=4\&lid=83, fecha de consulta: 29 de mayo de 2016. 27 Aparte de los citados, hace falta mencionar la novela Nove biografije (Nuevas biografias) de Milenko PAJIĆ (Beograd, Prosveta, 1987); libros de ensayos: Književnost i novi mit (Literatura y nuevo mito) de Srba IGNJATOVIĆ (Novi Sad, Bratstvo-Jedinstvo, 1988); Nedovršena rečenica (Frase interminada) de Đorđe RANDELJ (Novi Sad, Dnevnik, 2008); Do poslednjeg (u乞)daha (Hasta el último suspiro/ respiro) de Miloš LATINOVIĆ (Novi Sad, Adresa, 2010); U vrtlogu samoće, eseji o krizi duhounosti (En el vórtice de la soledad, ensayos sobre la crisis de espiritualidad) de Nemanja ROTAR (varias casas editoriales, 2003) y 2000 karaktera (2000 caracteres) del mismo autor (Pančevo, Libertatea, 2013); Ljubavna pisma i druge lekcije (Cartas de amor y otras lecciones) de Milisav SAVIĆ (Zrenjanin, Agora, 2012); igual que la monografía de Dejan MILUTINOVIĆ, Poetica Borgesiana: književevnost po H. L. Borhesu (Niš, Niški kulturni centar, 2015). 
Bojana Kovačević Petrović

\section{Los años ochenta y las influencias de García Márquez}

El verdadero boom de la novela hispanoamericana en Serbia empezó en 1973, con la publicación de Cien años de soledad de Gabriel García Márquez. "El libro pasó inicialmente desapercibido hasta que no fue mencionado por varios críticos y profesores de literatura en una encuesta anual del diario Politika de Belgrado como uno de los acontecimientos culturales más importantes del año." 28 Cinco años después fue publicado el número especial de la revista DELO, editada por Branko Anđić y Dalibor Soldatić y titulada Vavilonska biblioteka (Biblioteca de Babel), que ofreció un panorama de la nueva literatura hispanoamericana, con muy buenos textos de los dos editores, artículos sobre los nuevos escritores (Sábato, Benedetti, Paz, Yáñez, Rulfo, Carpentier, Fuentes, Roa Bastos, García Márquez, Puig, Vargas Llosa, Bryce Echenique, Donoso, etc.) y cuentos y capítulos de sus libros. "Fuimos conscientes de todos los libros que había que traducir y de lo poco que la literatura hispanoamericana estaba presente en nuestro país. Entonces empezamos a buscar gente que no tenía que ser hispanistas, pero que tenía un buen conocimiento de la lengua española y una gran cultura literaria." 29 Tras presentar la idea al editor jefe de la revista DELO, Jovica Aćin, quién la aceptó inmediatamente y publicó el emblemático número verde ${ }^{30}$, a Branko Anđić ${ }^{31}$ y Dalibor Soldatić ${ }^{32}$ se les ocurrió "gestionar una representación sistemática de las novelas latinoamericanas más importantes que tuvieron gran resonancia en el mundo." 33 Por suerte, los editores se interesaron, pero, por ejemplo, cuando Jasna Mimica tradujo al serbio Cien años de soledad "cinco casas editoriales rechazaron publicarla, simplemente porque no tenían

${ }^{28}$ Dalibor Soldatić, "Las literaturas hispánicas en Serbia", in: Colindancias. Revista de la Red Regional de Hispanistas de Hungría, Rumanía y Serbia, Timisoara: Editura Universitatii deVest, 2010, 1, 26, asequible en: http://dialnet.unirioja.es/descarga/articulo/5249353.pdf, fecha de consulta: 26 de enero de 2016.

${ }^{29}$ Branko ANĐIĆ, Comunicación personal, 7 de septiembre 2015.

${ }^{30}$ DELO, Vavilonska biblioteka, Nova hispanoamerickea književnost, agosto-septiembre de 1978/8-9.

${ }^{31}$ Es importante decir que Branko Anđić, aparte de traducir decenas de libros hispanoamericanos, también editó cuatro antologías del cuento hispanoamericano y argentino: la primera publicada en Serbia en la época de Yugoslavia fue Antologija savremene bispanoamerickee pripovetke (Antología del cuento hispanoamericano contemporáneo), Belgrado, Srpska književna zadruga, 1980; Antologija savremene argentinske priče (Antología del cuento argentino contemporáneo), Novi Sad, Svetovi, 2001; Otkačene priče Latinske Amerike (Cuentos guay de América Latina), Belgrado, Geopoetika, 2008; Borhesova deca (Los bijos de Borges: antología del cuento argentino contemporáneo), Novi Sad: Agora, 2012. Los tres últimos fueron editados con Lj. Popović Anđić.

32 Aparte de traducir decenas de libros, Soldatić se doctoró en la teoría de la novela de Mario Vargas Llosa y escribió dos importantes estudios: Prilozi za teoriju novog hispanoameričkog romana (La contribución a la teoría de la Nueva novela hispanoamericana), Belgrado, Facultad de Filología y Kragujevac, FILUM, 2002; y Svet hispanistike: uvod u studije (El mundo del hispanismo: introducción en los estudios) con Željko Donić, Belgrado, Zavod za udžbenike, 2011.

${ }^{33}$ Idem. 
noción del enorme éxito de ese libro en el mundo." 34 En cambio, según las palabras de Anđić, cuando el libro por fin fue publicado (en 1973), un año después cada serbio decente tenía un ejemplar en su casa, y lo había leído. Eso significa que el DELO verde y la traducción de Cien años de soledad abrieron paso a nuevas publicaciones de autores hispanoamericanos.

Uno de los escritores con obvia influencia de García Márquez es Milorad Pavić ${ }^{35}$. Investigando similitudes en la presencia de eros en los cuentos de Milorad Pavić y las novelas de Gabriel García Márquez, se podría decir que los dos autores presentan el eros como un principio eterno y que Pavić cultiva el erotismo de una manera específica, porque le pone características de lo mágico, y en eso se parece al escritor colombiano. ${ }^{36}$ Es importante decir que cinco libros de Milorad Pavić han sido traducidos al español: el mencionado Hazarski rečnik: roman-leksikon u 100.000 reči (Diccionario jázaro: novela léxico en 100.000 palabras, 1989), Predeo slikan čajem (Paisaje pintado con té, 1991) ${ }^{37}$, Unutrǎ̌nja strana vetra ili Roman o Heri $i$ Leandu (La cara interna del viento o La novela de Hero y Leandro, 1993) ${ }^{38}$, Sedam smrtnih grehova (Siete pecados capitales, 2003) ${ }^{39}$, Unikat (Pieza única: una novela delta 2007) ${ }^{40}$ y Drugo telo (Segundo cuerpo: una novela piadosa, 2011) ${ }^{41}$ y que en muchas de ellas reconocemos el ambiente del realismo mágico.

Entre varios ensayos que escribió Milan R. Simić figuran tres sobre la obra de García Márquez: "Pisci su ubice predumišljajem" ("Los escritores son asesinos con premeditación”), "Markesove otežnice” ("Las complicaciones de García Márquez”) y "O predosećajima starijih koji nisu prolazne stvari!” ("Sobre presentimientos de las personas mayores que no son cosas pasajeras"). También es interesante mencionar que el título de la novela El amor en los tiempos de cólera inspiró el título de la tertulia celebrada en el Instituto Cervantes de Belgrado: "El amor en los tiempos de la novela"42 en la cual participaron la escritora cubano-española Zoé Valdés y la escritora serbia Ljubica Arsić.

\footnotetext{
${ }^{34}$ Idem.

35 Véase el artículo de la joven hispanista serbia Ksenija VULOVIĆ, "Male of Female Time? Milorad Pavic's Dictionary of the Khazars and Gabriel García Márquez's One Hundred Years of Solitude", in: European Review, 23/3, 2015, 396-405.

${ }^{36}$ Rajko BLAGOJEVIĆ, "Eros u Pavićevim pričama i Markesovim romanima (Faktor istog u rečima različitog)", in: Leté́e violine Milorda Pavića, Actas del Congreso dedicado a Milorad Pavić, Novi Sad, Filozofski fakultet, 2015, 144-147, 146.

37 Traducción del serbocroata de Luisa Fernanda Garrido Ramos y Marina Ljujić, Barcelona, Anagrama.

${ }^{38}$ Traducción de Luisa Fernanda Garrido Ramos, Madrid: Espasa Calpe.

${ }^{39}$ Traducción del serbio Dubravka Sužnjević, México, Sexto Piso.

40 Traducción del serbio Dubravka Sužnjević, México, Sexto Piso.

${ }^{41}$ Traducción del serbio Dubravka Sužnjević, México, Sexto Piso.

42 Véase: http://belgrado.cervantes.es/FichasCultura/Ficha60529_58_1.htm, fecha de consulta: 10 de mayo de 2016.
} 
Bojana Kovačević Petrović

\section{Proyectos Cortázar}

Julio Cortázar se considera uno de los escritores hispanoamericanos más leídos en Serbia, con un gran número de traducciones publicadas entre 1969 y 2015. La primera traducción de su libro de cuentos (Las armas secretas) apareció mientras el boom vivía sus mejores momentos en Europa, y en las siguientes décadas creció el interés por su obra gracias a la traducción de Rayuela ${ }^{43}$ publicada en 1984 dentro de una de las dos ediciones tituladas "La novela hispanoamericana"44, editada por Dalibor Soldatić y Branko Anđić, junto con Milan Komnenić. Entre 1987 y 2012 Aleksandra Mančić tradujo los cuentos completos de Julio Cortázar, publicados por la casa editorial belgradense Rad, primero en libros separados seleccionados por la traductora, y después conjuntados en una edición de Cuentos completos en dos volúmenes (Editorial Službeni glasnik, 2012). Entre muchas otras cosas, en uno de los postfacios que contiene cada uno de los libros, la traductora y traductóloga serbia considera que "uno de los aspectos importantes de la literatura de Cortázar es la ética. Cortázar considera que un escritor tiene que participar activamente en la sociedad, y la manera más eficaz de afectar la realidad es a través de su literatura." $45 \mathrm{El}$ editor que apoyó todas esas publicaciones, (otra vez) Jovica Aćin, comentó que la traducción de los cuentos de Cortázar ha sido una de las empresas más significativas en su actividad editorial y que los cuentos que tenemos en serbio son excepcionales, así como la edición y la traducción. ${ }^{46}$ Considerando a Cortázar como uno de los narradores cruciales del siglo XX, Aćin añade que considera muy cercana su experiencia narrativa: "Opija me. I s tom drogom sam u večitom dijalogu."47

Una contribución muy importante a la lectura e interpretación de Julio Cortázar en Serbia la dio también el escritor y crítico Vasa Pavković, con la edición del Projekat Kortasar (Proyecto Cortázar, 2002), pidiendo a quince escritores serbios que escribieran cuentos para este libro. Su intención fue comprobar el impacto de los libros de

\footnotetext{
43 Traducción al serbio Silvia Monrós Stojaković, otra destacada traductora al serbio, de origen hispano.

${ }^{44}$ La primera edición, publicada en 1984, contenía las traducciones de las siguientes novelas: Yo el Supremo de Augusto Roa Bastos, El astillero de Juan Carlos Onetti, Rayuela de Julio Cortázar, Conversación en la Catedral de Mario Vargas Llosa, Sobre héroes y tumbas de Ernesto Sábato; y la segunda, publicada en 1985, una nueva traducción de Cien años de soledad de Gabriel García Márquez, Terra Nostra de Carlos Fuentes, El beso de la mujer araña de Manuel Puig, El obsceno pájaro de la noche de José Donoso El siglo de las luces de Alejo Carpentier. Los libros fueron publicados como una colaboración de varias casas editoriales: Prosveta, Narodna knjiga, Književne novine, Partizanska knjiga y Rad de Belgrado; Svjetlost de Sarajevo y Tiskarna Ljudske pravice de Ljubljana).

45 Važan aspekt Kortasarove književnosti je i etika. Kortasar veruje da pisac mora delovati i u društvu, i da kroz književnost najdelotvornije može uticati na stvarnost. (Tr. aut.). Aleksandra MANČIĆ MILIĆ, "Postfacio", in: KORTASAR, Hulio, Apokalipsa u Solentinameu, Belgrado, Rad, 1998, 134.

46 Aćin, comunicación personal, 11 de junio 2016.

${ }^{47}$ Me embriaga. Y con ese narcótico estoy en permanente diálogo. (Tr. aut.). Idem.
} 
Cortázar en los escritores serbios contemporáneos, cuyos cuentos "de diferentes poéticas y generaciones, a veces parten de los cuentos de Cortázar, sus imágenes, motivos, ideas, y a veces el impacto del gran escritor se puede más percibir que explicar con un procedimiento analítico." ${ }^{48} \mathrm{El}$ libro consta de quince cuentos inspirados en el escritor argentino, directa o indirectamente. Por ejemplo, el cuento de Snežana Bukal se titula "Final del juego" igual que el cortazariano; Edvard Jukić escribe sobre "La casa Ciclada"; en el cuento de Miloš Latinović "Capítulos prescindibles" uno de los protagonistas se llama Julio Denis (el seudónimo de Cortázar utilizado a principios de su carrera literaria) y el cuento termina con las palabras “¿Encontraría a la Maga?, con las cuales empieza Rayuela de Cortázar; el relato de Milovan Marčetić se titula "Carta a una señorita" como referencia al cuento cortazariano "Carta a una señorita en París" de su libro Bestiario; Vasa Pavković optó por titular su relato "A Esperanza Machado", a propósito del cuento "Alguien que anda por ahí" dedicado a la pianista cubana, y lo escribió en los ritmos de música habanera y en seis frases larguísimas; Jasmina Topić tituló su cuento "Casa tomada", igual que Cortázar el suyo, publicado en 1946. Se trata de uno de los proyectos más significativos relacionados con la recepción de la obra de un escritor hispanoamericano en Serbia y la idea en gran medida ha sido justificada por la calidad de los cuentos.

En cuanto a la relación entre Julio Cortázar y Milorad Pavić, en 2015, a propósito de los treinta años de la publicación de Diccionario jázaro, fueron publicados actas dedicadas a la obra del autor serbio, con artículos escritos de parte de los investigadores jóvenes. En el texto titulado "Encuentro de Pavić y Cortázar: búsqueda de la forma de lectura como búsqueda de identidad”, Viktor Škorić considera que Pavić es el hermano menor de Julio Cortázar ${ }^{49}$, que el elemento crucial de los dos escritores es el juego y que el encuentro de la obra de Pavić y Cortázar “es, para nosotros, el encuentro del este con el oeste, dos literaturas, serbia y latinoamericana, que consiguieron realizar el boom mundial." 50

\footnotetext{
48 "različitih poetika i generacijske pripadnosti, pokatkad prolaze od Kortasarovih priča, slika, motiva, ideja, a pokatkad se podsticaj velikog pisca više naslućuje nego što bi bio obrazloživ ma kojom analitičkom procedurom." (Tr. aut.). Vasa PAVKOVIĆ, "Kortasar pripovedač", in: Projekat Kortasar, Kraljevo, Povelja, 2002, 132.

49 Viktor ŠKORIĆ, "Susret Pavića i Kortasara: potraga za formom čitanja kao potraga za identitetom", in: Letéce violine Milorda Pavića, zbornik povodom trideset godina od štampanja romana Hazarski rečnik, Novi Sad, Filozofski fakultet, 2015, 134-143. La cita está en la página 137.

50 “za nas predstavlja susret istoka i zapada, dveju književnosti, srpske i latinoameričke, koje su uspele da ostvare svetski bum.” (Tr. aut.). Ibidem, 141.
} 
Bojana Kovačević Petrović

\section{Carlos Fuentes y los Balcanes}

Carlos Fuentes, como hemos mencionado, fue el primer autor del boom traducido en Serbia. En las últimas cinco décadas se publicaron once libros suyos, entre los cuales figuran nueve novelas. Después de la publicación de La muerte de Artemio Cruz en 196951 , en 1978 apareció la excelente traducción de la novela $A u r a^{52}$, la obra de Fuentes más leída e investigada. Además, ese libro forma parte de uno de los temas de la asignatura "Escritura creativa" del profesor Sava Damjanov. En la entrevista que le hicimos a propósito de nuestras investigaciones, el Dr. Damjanov comentó que consideraba el mayor cumplido para un escritor la fascinación de los estudiantes por su obra. "Para Fuentes, igual que para Pavić, es imprescindible que le lean lectores talentosos. Ninguna obra puede vivir si, por ejemplo, es canonizada o tematizada en cinco tesis doctorales. Los jóvenes de 25 años vivirán mucho tiempo todavía, seguirán viviendo después de nosotros; Fuentes, Pavić y Borges ya no están vivos, pero su obra está viva en cabezas y recepciones de calidad; y la literatura sigue viva de la mejor manera a través de la lectura." 53

El profesor de la Facultad de Filosofía y Letras de la Universidad de Novi Sad considera que Aura de Fuentes es una de pocas creaciones artísticas con verdadera aura, lingüística y literaria, con una magia difícil de definir que hechiza al lector. ${ }^{54}$ Otro escritor serbio, directamente influido por una obra de Carlos Fuentes, es Goran Petrović, cuya novela Opsada crkve Svetog Spasa (El cerco de la Iglesia de la Santa Salvación) fue escrita cuando el autor serbio leyó Terra Nostra de Carlos Fuentes. Deseando escribir "la Terra Nostra serbia", "argumento que, con su acción condensada y el ambiente fuentesiano, mantendría al lector en permanente incertidumbre, en una fina línea entre historia y ficción“ “55, Petrović creó uno de los mejores libros de la literatura

${ }^{51}$ En el artículo "El palacio de Diocleciano en las novelas Terra Nostra y Cumpleaños de Carlos Fuentes", publicado en las Actas del congreso "Jezici i kulture u vremenu i prostoru 5" llevado a cabo en octubre de 2015 en la Facultad de Filosofía y Letras de la Universidad de Novi Sad, Serbia, la autora de este texto ha investigado el interés del autor mexicano en la construcción ubicada en la costa dálmata y llegó a la conclusión de que el Palacio de Diocleciano tenía el mismo valor histórico y cultural que El Escorial, al cual se parece mucho, y que Carlos Fuentes en el monumento del rey romano reconoció la necrópolis del rey Felipe II.

${ }^{52}$ Hecha por Branko Anđić y publicada por la casa editorial Prosveta en 1978.

53 “'Za Fuentesa, isto kao i za Pavića, dragoceno je to što ga čitaju daroviti ljudi, talentovani čitaoci. Nijedno delo neće živeti zahvaljujući tome što je kanonizovano ili što je o njemu napisano pet doktorata. Mladi ljudi od 25 godina živeće mnogo posle nas, Fuentesa, Pavić i Borhes više nisu živi, ali je njihovo delo u nekim kvalitetnim glavama i recepcijama živo, a pravi način života književnost je kroz čitanje.” (Tr. aut.). Sava DAMJANOV, Comunicación personal, 19 de enero 2016.

${ }^{54}$ Idem.

55 "Povest koja bi, zgusnutom radnjom i fuentesovskom atmosferom, držala čitaoca u stalnoj neizvesnosti, na tankoj ivici između istorije i fikcije." (Tr. aut.) Bojana KOVAČEVIĆ PETROVIĆ, 
El impacto del boom latinoamericano en los escritores serbios

serbia del siglo XX, una obra maestra elogiada y premiada. La metáfora de la historia, El Escorial de Terra Nostra en la narración serbia es el Monasterio Žiča: el centro de la estructura y el lugar del encuentro, pero "Para un libro no es suficiente que reconstruya una época, eso tal vez tiene más que ver con la habilidad que con el arte; es mucho más importante que esa época explique la época en la que vivimos, y que tenga valor para alguna otra época futura." 56

Para las futuras investigaciones queremos recomendar también la investigación de otra hispanista serbia, Jelena Nađ, que hizo su tesis de maestría sobre la "Traducción y edición de la literatura serbia en México".

\section{Vargas Llosa en directo}

Según el tiraje de sus libros y el número de sus traducciones, Mario Vargas Llosa es uno de los escritores hispanoamericanos más leídos en Serbia, desde la publicación de la versión serbia de su novela Conversación en la Catedral (1984) hasta hoy. ${ }^{57}$ Hay muchos escritores que escriben sobre la obra de Vargas Llosa y bajo su influencia, y en nuestro artículo mencionaremos algunos. Uglješa Šajtinac, laureado del European Union Prize for Literature 2015, es uno de los mejores conocedores/lectores de la obra del premio nobel peruano, y en la entrevista que hicimos para este artículo, nos comentó lo siguiente: "Conversación en la Catedral, La guerra del fin del mundo, La tía Julia y el escribidor, tan como La ciudad y los perros de Mario Vargas Llosa las leí a la edad de entre 16 y 18 años. El poder aterrador del montaje de los flujos narrativos de Vargas Llosa produjo una verdadera explosión en mi percepción como lector. No me atrevería a decir que me dio ánimo en el plano del volumen del material narrativo - ese número de páginas para mi es inalcanzable. Sin embargo, en términos de las pasiones de los protagonistas, su

\footnotetext{
"Pogled na evropsku istoriju i kulturu u romanu Terra Nostra Karlosa Fuentesa", in: Anuario de la Facultad de Filosofía de la Universidad de Novi Sad (eds.: dra. Vladislava GORDIĆ PETKOVIĆ y dr. Dušan MARINKOVIĆ), libro Xl-1, Novi Sad, Filozofski fakultet, 2015, 107-128, 124, asequible en: http://epub.ff.uns.ac.rs/index.php/gff/article/view/1495, fecha de consulta: 26 de mayo de 2016. 56 “Za jednu knjigu nije dovoljno rekonstruisati jednu epohu - to je možda više pitanje veštine nego umetnosti - već je važno da ta epoha objašnjava epohu u kojoj mi živimo, i da ona bude vredna za neku drugu, buduću epohu.” (Tr. aut.). Goran Petrović, Comunicación personal, 26 de junio 2015, en Bojana KOVAČEVIĆ PETROVIĆ: "Aspectos de la historia y cultura europea en la novela Terra Nostra de Carlos Fuentes", in: Anuario de la Facultad de Filosofía de la Universidad de Novi Sad (eds.: dra. Vladislava GORDIĆ PETKOVIĆ y dr. Dušan MARINKOVIĆ), libro Xl-1, Novi Sad, Filozofski fakultet, 2015, 107-128.

${ }^{57}$ Una de las razones del interés recientemente aumentado en la obra de Vargas Llosa fue la estancia del escritor peruano en Serbia en junio 2015, cuando le fue organizada una tertulia en el Teatro Nacional Serbio a la cual asistieron aproximadamente 1.400 personas. Véase: https://www.youtube.com/watch?v=fWcXGRhMCK4, y http://www.laguna.rs/v3742_vest_ nezapamcena_poseta_na_dodeli_nagrade_mariju_vargasu_ljosi_u_novom_sadu_laguna.html, fecha de consulta: 20 de mayo de 2016.
} 
colisión con la realidad y la relación completamente casual hacia lo moral, único y claramente perceptible, siempre he tratado de intentar lo mismo, de imitarle, de manera casi fanáticamente religiosa. ${ }^{58}$

Entre los escritores y críticos que han reflexionado en varias ocasiones sobre la obra de Mario Vargas Llosa, queremos destacar a Jasmina Vrbavac, autora y periodista, cuya reseña sobre las Travesuras de la niña mala ${ }^{59}$ fue publicada en el programa cultural televisivo Metropolis en 2008. Por otro lado, en su libro Tri $i$ po (Tres y media), entre varios ensayos y reseñas, Jasmina Vrbavac publicó uno sobre "Erótica y literatura" dedicado a Los cuadernos de don Rigoberto de Vargas Llosa y la novela Noche blanca de amor de Gustaw HerlingGrudziński como ejemplo de ambivalencia en la noción e interpretación del erotismo. ${ }^{60}$

En el momento cuando estuvimos a punto de terminar este artículo descubrimos que otro autor y editor serbio, Aleksandar Šurbatović estaba terminando su novela, que llevaría el título Balade o strašnom skladu (Baladas sobre la terrible armonía) o Telemabija (Telemaquia), y sería una historia sobre tres jóvenes en el turbulento período de 19961997 en Serbia, en busca de su propia identidad a través de la relación con uno de sus padres: intentando llegar a conocer a sus padres, subconscientemente esperan conocerse a sí mismos. El libro será un homenaje a grandes novelas hispanoamericanas: Sobre héroes y tumbas de Ernesto Sábato, El siglo de las luces de Alejo Carpentier y sobre todo Conversación en la Catedral de Vargas Llosa, por los diálogos entrecruzados, uso de leitmotivos, hipertextualidad y fragmentación. ${ }^{61}$

\section{Conclusiones}

Como hemos visto, la literatura hispanoamericana, sobre todo la obra de Jorge Luis Borges y los escritores de la nueva novela hispanoamericana: Cortázar, Fuentes, García Márquez y Vargas Llosa, han tenido un gran impacto en los escritores serbios en las últimas cinco décadas. Aparte de los hispanistas de este país -que durante ese periodo escribieron decenas de artículos académicos sobre la obra de los escritores hispanoamericanos- hay un gran número de autores serbios que fueron influidos por la literatura de ese continente. Entre ellos, hemos destacado a Vasko Popa, Milorad Pavić, Danilo Kiš, Vasa Pavković y Goran Petrović.

\footnotetext{
58 Razgovor u Katedrali, Rat za smak sveta i Tetka Huliju i piskaralo kao i Grad i psi Marija Vargasa Ljose pročitao sam u dobi od 16-18 godine. Zastrašujuća moć Ljosine montaže pripovednih tokova raznela je moju čitalačku percepciju. Ne bih se usudio da tvrdim kako me je na planu obima pripovedačkog materijala ohrabrio - za mene su to nedostižni brojevi stranica. Međutim, na planu sleda strasti glavnih junaka, njihovog sudara sa stvarnošć i potpuno neobaveznog odnosa spram jednog jedinog i jasno uočljivog morala, tu sam se oduvek trudio da pokušavam isto, gotovo fanatički religiozno. (Tr. aut.). Uglješa ŠTAJTINAC, Comunicación personal, 29 de junio 2016.

59 "Između uživanja i zadovoljstva" ("Entre el gozo y el placer"), in: Identidad en la brecha, Agora, 2012.

${ }^{60}$ Jasmina VRBAVAC, Tri i po. Kritike, Zrenjanin, Agora, 2007, 121.

${ }^{61}$ Aleksandar ŠURBATOVIĆ, Comunicación personal, 30 de junio 2016.
} 
En este artículo no podíamos presentar todas las influencias visibles y alcanzables, pero hemos intentado hacer un repaso de los casos que hemos considerado importantes e interesantes, aunque hay muchos más, porque cada año se traducen al serbio varios libros de escritores que no pertenecieron al boom, pero su influencia no es tan obvia. Al reflexionar sobre los motivos del gran interés de los escritores serbios en la literatura hispanoamericana, diríamos que estamos de acuerdo con el escritor y profesor Sava Damjanov quien cree que entre las posibles razones destaca la posición geopoética y geocultural de los Balcanes, sobre todo por las mezclas de culturas y el mestizaje de las nacionalidades, que no cesa con el paso de los siglos.

Aparte de investigar el impacto de una literatura en otra, nuestro artículo ha pretendido ofrecer una perspectiva de la creación literaria desde el punto de vista hispano en Serbia, que consideramos un campo todavía desconocido fuera de las fronteras nacionales o regionales, y un verdadero Eldorado para la ciencia y los investigadores de todo el mundo.

Finalmente, con este artículo queríamos abrir un nuevo tema para estudiar e investigar en el futuro: el impacto de los escritores serbios y la cultura de esta parte de Europa en los escritores hispanoamericanos. Para mencionar solo unos ejemplos, diremos que Alfonso Reyes escribió un ensayo titulado "La pasión de Serbia", Liliana Heer dedicó un capítulo de su novela El sol después a la poetisa serbia Desanka Maksimović y Roberto Bolaño ha basado uno de los personajes de 2666 en los conocimientos sobre Jovica Aćin. 